\title{
"Half decadal trend of maternal deaths occurred in a tertiary care hospital of Rajasthan"
}

\author{
${ }^{1}$ Dr. Chandrakanta Sulaniya, ${ }^{2}$ Dr Pawan Kumar Sulaniya, ${ }^{3}$ Dr. Kusum Lata \\ Gaur, ${ }^{4}$ Dr Anju Sharma, ${ }^{5}$ Dr. Bhanwer Singh Meena, \\ ${ }^{1}$ Senior Resident, Department of Obstetrics \& Gynecology, SMS Medical College, Jaipur (Raj.) India \\ ${ }^{2}$ Assistant Professor, Department of Pediatrics, SMS Medical College, Jaipur (Raj) India. \\ ${ }^{3}$ Professor and WHO Fellow IEC, Department of Community Medicine, SMS Medical College, Jaipur (Raj.) \\ India \\ ${ }^{4,5}$ Professor, Department of Obstetrics \& Gynecology, SMS Medical College, Jaipur (Raj) India.
}

\begin{abstract}
:
Background: India contributes one fourth of total world maternal deaths. Millennium Development Goal set to reduce maternal mortality upto or less than 109 per lakh of total live births which is far away from present level specially in Rajasthan ${ }^{2}$

Objective: To know the trend of maternal deaths occurring in last five year (2005-2009). Materials and Methods: Records of verbal autopsies of maternal deaths occurred in Mahila Chikitsalya Jaipur since $1^{\text {st }}$ Jan. 2005 to $31^{\text {st }}$ Dec. 2009. Available data in the autopsy records of maternal deaths were collected and then these data were entered in MS Excel 2007 worksheet. These data were classified and presented in percentage and proportion. Chi-square and ANOVA test of significance were used to interpret data.

Results: Overall 193 maternal mortality per lakh of total live births was observed in year 2005-2009 with maximum MMR in 2008 (236/lakh TLBs) and minimum MMR in Year 2009 (133/lakh TLBs) which has significant variation. Total 133 maternal deaths occurred in study period of five years. Although maximum maternal deaths (69 i.e. $51.88 \%$ ) occurred in 21 to 25 years group but age-wise variation was not found significant $(p>0.05)$. Maternal deaths were significantly more in un-booked cases, within 24 hours of addimission and in post-partum period with rural predominance than unbooked cases, after 24 hours of addimission, in other maternal death period and urban females respectively.

Conclusions: Maternal deaths were found to significantly vary with time but not with season and age of mother. These deaths were also found significantly more in un-booked cases, within $24 \mathrm{hrs}$ of addimission and in postpartum period with rural predominance than their counterparts
\end{abstract}

Key words: Maternal deaths, Trend, Verbal Autopsy, MMR, TLBs

\section{Introduction}

According to the World Health Organization (WHO), "A maternal death is defined as death of a woman while pregnant or within 42 days of termination of pregnancy, irrespective of the duration and site of pregnancy, from any cause related to or aggravated by pregnancy or its management" (ICD-10). Almost half a million women die every year from complications during pregnancy and childbirth. About $99 \%$ of these women are from developing world with over $90 \%$ concentrated in Africa and Asia. ${ }^{1}$

World Health Organization estimates that globally 358,000 women die every year due to pregnancyrelated complications out of that India contributes one fourth of these maternal deaths. ${ }^{2}$ The Millennium Development Goals of the United Nations has set the target of achieving 109 maternal deaths/1,00,000 live births by $2015 .{ }^{3}$ Within India, there is marked variation in MMR and healthcare access between regions and in socioeconomic factors ${ }^{4,5}$. India contributes approximately 63,000 maternal deaths each year .National average of MMR IS 212/100000 live births.(RGI 2007-2009)

MMR in India, though far from the target set by MGD, has declined from 254 in 2004 to 212 in 2007 but in some states including Rajasthan MMR is still very high. Rajasthan has 318 maternal death/1,00,000 total live births.?

So, this present study was conducted to know the trend of maternal deaths in last five years on with verbal autopsy of maternal deaths occurring in a tertiary level hospital of western Rajasthan. 


\section{Materials and Methods}

A record base cross-sectional study was conducted on records of verbal autopsies of maternal deaths occurred in Mahila Chikitsalya Jaipur, which is a tertiary level hospital attached to SMS Medical College, Jaipur. Records of verbal autopsies of maternal deaths occurred in Mahila Chikitsalya Jaipur since $1^{\text {st }}$ Jan. 2005 to $31^{\text {st }}$ Dec. 2009.

All verbal autopsy forms recording death of women in pregnancy, or 42 day post-abortion, or 42 days post-partum or due to reason that had been assigned an ICD-10 O-code (obstetric causes) of three-digit International Classification of Diseases and Related Health Problems, 10th revision (ICD-10) ${ }^{5}$

Data available in these records were collected and compiled in the form of master chart in Microsoft MS excel sheet 2007. These data were classified and analyzed with the help of computer and presented in figures and percentage and proportions. Chi-square and ANOVA test of significance were used to interpret data.

\section{Result}

Out of total 68870 total live births, 133 maternal deaths occurred in study period of five years revealing overall Maternal Mortality Rate (MMR) 1.93 per thousand total live births (193/1,00,000 TLBs) with maximum MMR (236/1,00,000 TLBs) was observed in year 2008. In last year of survey (2009) it was observed only $133 / 1,00,000$ TLBs and this trend of MMR was having significant variation $(\mathrm{p}=0.346)$.

Out of total 133 maternal deaths occurred in study period of five years, maximum deaths i.e. 35 (26.32\%) were observed in 2008. It was observed that maternal deaths were continuously on increase from year 2005 to year 2008 after that it was decreased in year 2009. It was also observed in this study that although there was a sudden increase in number of deaths in June 2008 but variation in number of maternal deaths as per season was not found significant $(\mathrm{p}>0.05)$ in any year.

It was also depicted from this study that although maximum deaths (69 i.e. $51.88 \%$ ) occurred in 21 to 25 years group followed by number of deaths in age group of 26 to 30 years but this variation was not found significant ( $>0.05$ ). Likewise, when mean age at death of mother was compared with the time no significant difference was observed $(\mathrm{p}>0.05)$

It was also observed that maternal death was significantly more $(p<0.001)$ in rural mothers than the urban $(89 \mathrm{v} / \mathrm{s} 44$ i.e. $66.92 \% \mathrm{v} / \mathrm{s} 33.08 \%)$.

Majority maternal deaths i.e. 120 (90.23\%) were observed in unbooked pregnancies which was found significant $(\mathrm{p}<0.001)$. Likewise it was also observed that majority maternal deaths i.e. $115(86.47 \%)$ were occurred within 24 hours of addimission which was also found significant $(\mathrm{p}<0.001)$.

In about half of maternal deaths i.e. $66(49.62 \%)$ occur in post-partum period followed by ante-partum and intra-partum period which was also found significant $(\mathrm{p}<0.001)$. Like wise primi-gravida contributes about half of the maternal deaths ( 65 i.e. $48.87 \%$ ) but it was not found significant ( $p>0.05)$.

\section{Discussion}

A 5 yrs retrospective study of maternal mortality and its common complications leading to maternal death was conducted. A retrospective study of hospital records and death summaries of all maternal deaths over 5 yr periods was carried out since Jan 2005 to Dec 2009.

In the present study overall MMR was observed 193/1,00,000 TLBs majority of women (115 i.e. 86.47.\%) died within $24 \mathrm{hrs}$ of admission. In contrast to the findings of present study many of authors $1,8,9,10,11$ reported MMR in range of 230 to $454 /$ lakh TLBs. Murthy etall ${ }^{1}$. Onakewhor JU etall ${ }^{8}$ Kumar R etall ${ }^{9}$ Nusrat N et all ${ }^{10}$ and Jadhav et all ${ }^{11}$ reported 302, 454, 230, 297 and 395/lakh TLBs respectivly. This may be explained that Mahila Chikitsalay where this study was conducted is a premier tertiary care hospital of Rajasthan. This was further supported by findings of Chawala etall ${ }^{12}$, who reported MMR only 85.42/lakh TLBs. MMR is observed much lower of Kerala Tamil Nadu and Maharashtra, 81, 97 and 104 respectively. These are the three states in India which have realized the MDG target of MMR 209. At global level, WHO studies show there is much variability between countries, with MMR of 290 in developing regions as compared with 14 in developed regions. ${ }^{13}$

In the present study significantly more maternal deaths were reported in age group of 25-30 yrs (\%) with predominance of rural area women. In contrast to this Murthy etall ${ }^{1}$ reported that out of total 120 maternal deaths most of deaths occurred in the age group of 20-24 years and likewise Jadhav et all ${ }^{11}$ study shows maximum of maternal deaths $(75.1 \%)$ were in $>20$ years and $<30$ years of age. But well supported findings were of Onakewhor JU etall ${ }^{8}$ and Puri Alka et all ${ }^{14}$ Onakewhor JU etall ${ }^{8}$ reported maternal death women of 20-39 years $81.3 \%$ with $9.4 \%$ teenage deaths and Puri Alka et all ${ }^{14}$ study showed that $71.53 \%$ of women die between the age 21 and 30 years.

There were significantly more maternal deaths were observed of rural mothers than the urban in the present study $(66.92 \% \mathrm{v} / \mathrm{s} 33.08 \%)$. Well comparable findings were of Murthy etall, who also reported 
significantly more maternal deaths from rural areas $(69.16 \%)$ as compared to women from urban areas $(30.83 \%)$.

In the present study there was no significant variation was observed in gravid -wise whereas Murthy etall $^{1}$ and Onakewhor $\mathrm{JU}$ etall ${ }^{8}$ reported more deaths in multiparas than nulliparas, who reported $56.66 \%$ and $62.5 \%$ deaths in multiparas respectively.

In the present study significantly more maternal deaths were observed in un-booked than booked cases $(90.23 \% \mathrm{v} / \mathrm{s} 9.77 \%)$. Almost similar was observed by Puri Alka et all ${ }^{14}$ who reported that $92.30 \%$ of women died were unbooked while $1.53 \%$ were booked cases. Murthy et.all ${ }^{1}$ also reported significantly more maternal deaths were reported in unbooked patients $(83.33 \%)$ as compared to booked patients $(16.66 \%)$. Even Jadhav et $\mathrm{all}^{11}$ also has well comparable observation to present study i.e. $78.48 \%$ deaths in booked and $21.51 \%$ deaths in unbooked cases.

In the present study although there were more deaths in multipara than nulliparas but this difference was not significant. Almost similar observations were made by Murthy etall ${ }^{1}$, Onakewhor JU etall ${ }^{8}$, Jadhav et all $^{11}$ and Puri Alka et all ${ }^{14}$ who also reported more deaths in multiparas than nulliparas, who reported $56.66 \%$, $62.5 \%, 50.64 \%$ and $51.33 \%$ maternal deaths in multiparas respectively.

There were significantly more maternal deaths were observed in post natal period and within 24 hours in the present study. Well comparable findings were of other authors like Murthy etall ${ }^{1}$, Onakewhor JU etall ${ }^{8}$, Jadhav et all ${ }^{11}$ and Puri Alka et all ${ }^{14}$

\section{Conclusion:}

MMR is observed little higher to national average in the present study. Maternal deaths were without year-wise, season-wise, age wise and gravid -wise significant variation. But these maternal deaths were significantly more in un-booked cases, within 24 hours of addimission and in post-partum period with rural predominance than unbooked cases, after 24 hours of addimission, in other maternal death period and urban females respectively.

\section{References:}

[1]. Murthy BK, Murthy MB, Prabhu PM. Maternal mortality in a Tertiary care Hospital: A 10 year Review. Int J Pre. Med; 2013 Jan 4(1): $105-9$

[2]. World Health Organization (WHO), UNICEF, UNFPA, and The World Bank estimates. Trends in maternal mortality: 1990 to 2010. Department of Reproductive Health and Research WHO; 2012

[3]. World Health Organisation: Health and millennium development goals. Geneva: World Health Organisation; 2005.

[4]. IIPS (2010) District level household and facility survey (DLHS-3) 2007-2008: India. Mumbai: International Institute for Population Sciences.

[5]. Barros AJD, Ronsmans C, Axelson H, Loaiza E, Bertoldi AD, et al. (2012) Equity in maternal, newborn, and child health interventions in countdown to 2015: a retrospective review of survey data from 54 countries. Lancet 379: 1225-1233. Doi: 10.1016/s0140-6736(12)60113-5

[6]. Jadhav CA , Gavandi Prabhakar, Shinde MA, Tirankar VR;Maternal Mortality: Five Year Expirience in Tertiary care Centre.Indian Journal of Basic \& Applied Medical Reaserch ; June 2013: Issue-7,Vol.-2,P.702-709

[7]. Office of Registrar General, India, Ministry of Home Affairs. Special bulletin on maternal mortality in India: 2007-2009, Sample Registration System [Internet]. New Delhi, India: Office of Registrar General, India; 2011

[8]. Onakewhor JU, Gharoro EP. Changing trend in maternal mortality in developing country.Niger J Clin Pract 2008 June; $11(2)$ : 111 20

[9]. Kumar R, Sharma AK, Barik S, Kumar V. Maternal Mortality Inquery in a rural community of north India. Int J Gynaecol Obstet 1989 Aug; 29(4): 313-9

[10]. Nusarat N and Nisar AS. Maternal mortality in rural community: A challenge for achieving Millennium Development Goal . J Pak Med. Assoc 2010 Jan; 60(1):20-23

[11]. Jadhav CA, Gavandi Prabhakar, Shinde MA, Tirankar VR;Maternal Mortality: Five Year Expirience in Tertiary care Centre.Indian Journal of Basic \& Applied Medical Reaserch ; June 2013: Issue-7,Vol.-2,P.702-709

[12]. Chawla I, Saha MK, Akhtarkharvi A. Maternal mortality in andaman and nicobar group of islands: 10 years retrospective study.Indian J Community Med. 2014 Jan; 39(1):35-7

[13]. Maternal mortality. Geneva: World Health Organization; 2010 (Fact Sheet No. 348).

[14]. Puri Alka, Yadav Indra, Jain Nisha : Maternal Mortality in an Urban Tertiary Care Hospital of North India;The Journal of obst etrics and Gynaecology of India May/June 2011 pg 280-285 

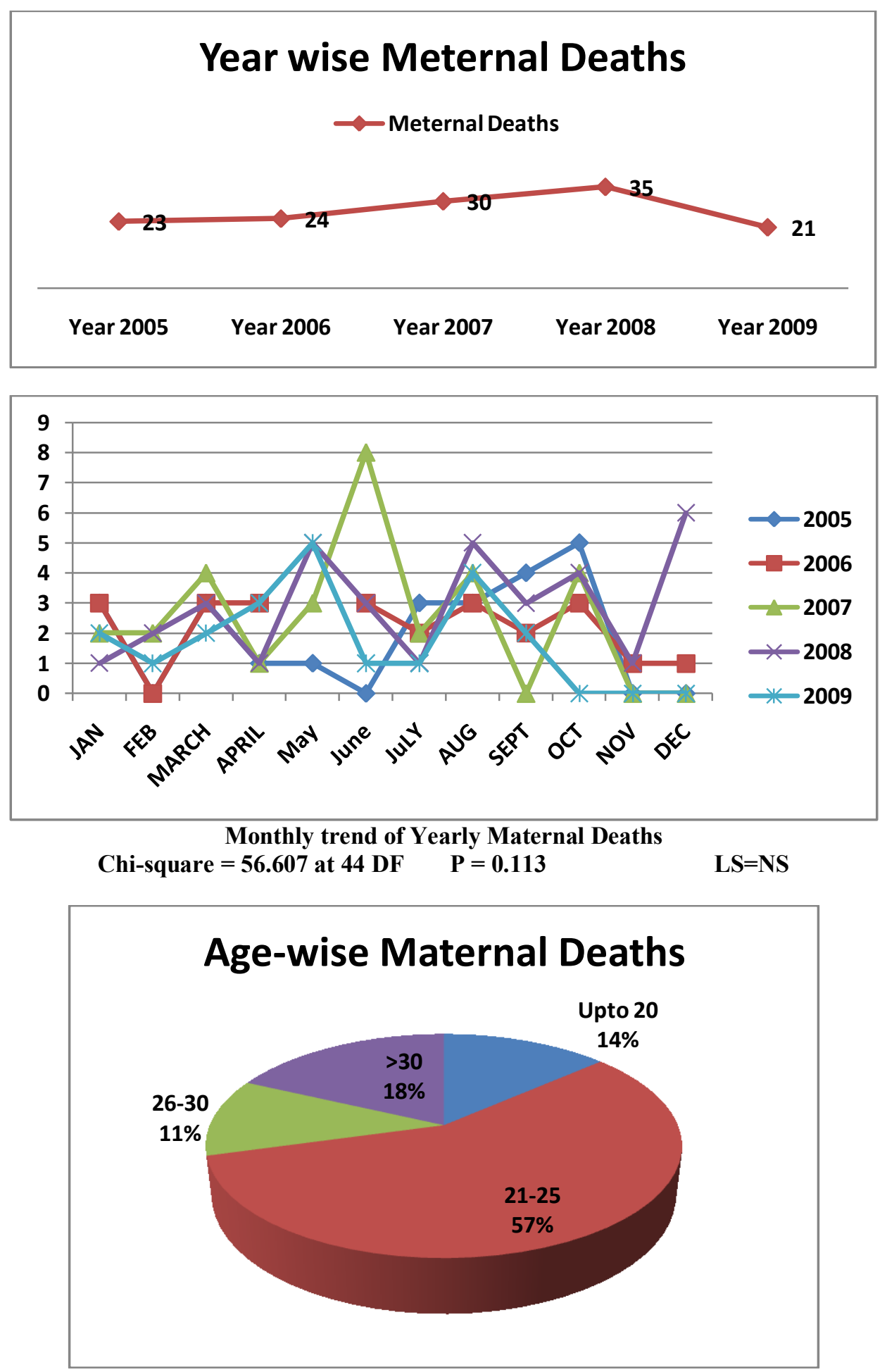


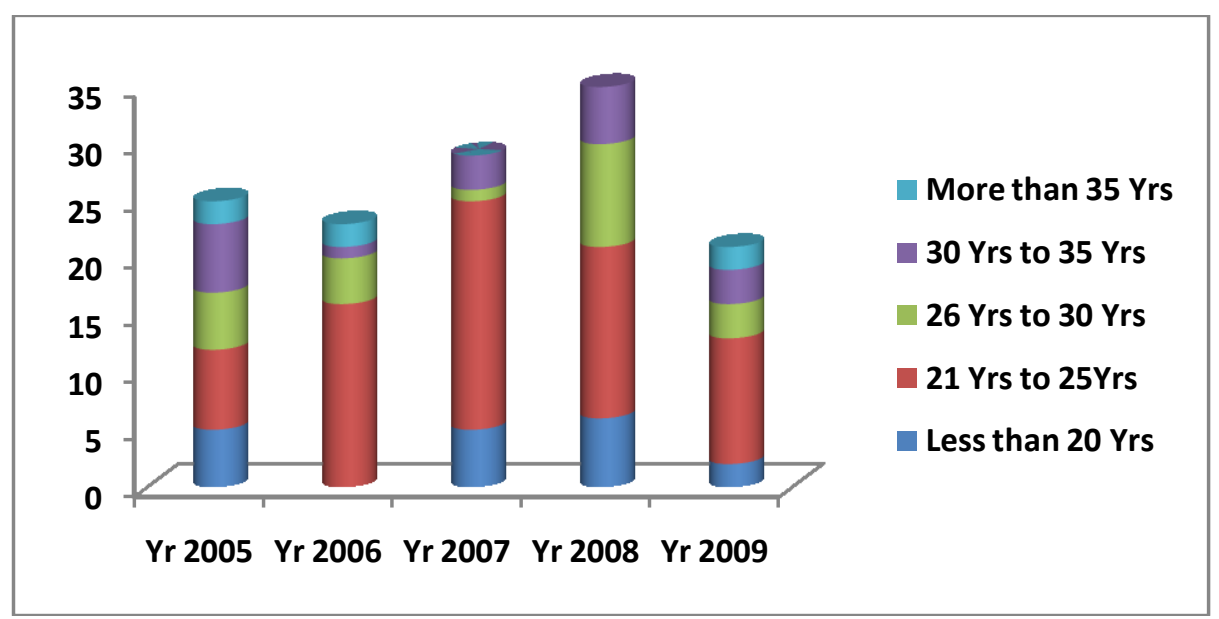

Age wise maternal death trend from year 2005 to 2009

Table No. 1 Maternal Mortality Ratio (MMR) trend from year 2005 to 2009

\begin{tabular}{|c|l|c|c|c|}
\hline S. No. & Year & Total No. of Live Births & Number of Maternal Deaths & $\begin{array}{c}\text { MMR } \\
\text { Maternal Deaths /Lakh TLBs }\end{array}$ \\
\hline $\mathbf{1}$ & Yr 2005 & 11123 & 23 & 207 \\
\hline $\mathbf{2}$ & Yr 2006 & 12433 & 24 & 193 \\
\hline $\mathbf{3}$ & Yr 2007 & 14677 & 30 & 204 \\
\hline $\mathbf{4}$ & Yr 2008 & 14823 & 35 & 236 \\
\hline $\mathbf{5}$ & Yr 2009 & 15814 & 21 & 133 \\
\hline $\mathbf{6}$ & Total & 68870 & 133 & 193 \\
\hline
\end{tabular}

Chi-square Test $=170.675$ at $4 \mathrm{DF}$

$\mathbf{P}<\mathbf{0 . 0 0 1}$

$\mathbf{L S}=\mathbf{S}$

Table No. 2 Age wise maternal death trend from year 2005 to 2009

\begin{tabular}{|c|c|c|c|}
\hline S. No. & Year & Mean Age at Death & SD of Age at Death \\
\hline $\mathbf{1}$ & Yr 2005 & 27.28 & 6.85 \\
\hline $\mathbf{2}$ & Yr 2006 & 26.22 & 6.28 \\
\hline $\mathbf{3}$ & Yr 2007 & 24.38 & 4.25 \\
\hline $\mathbf{4}$ & Yr 2008 & 25.63 & 4.89 \\
\hline $\mathbf{5}$ & Yr 2009 & 27 & 5.81 \\
\hline \multicolumn{2}{|r|}{ ANOVA (F) $=\mathbf{1 . 1 4}$ at 131DF $\quad$ P $=\mathbf{0 . 3 4 3}$} \\
\hline
\end{tabular}

Table No. 3 Age wise maternal death trend from year 2005 to 2009

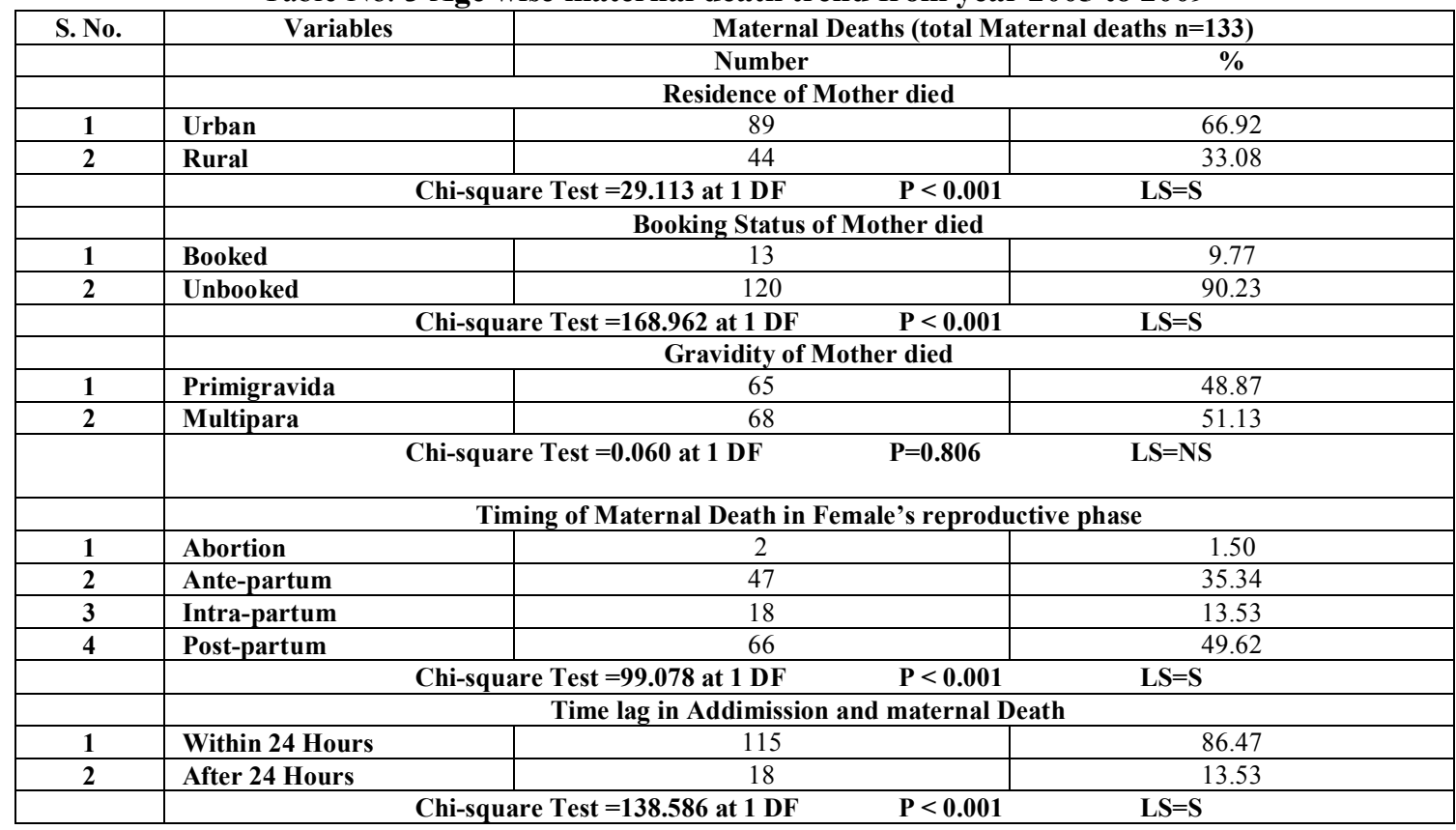

